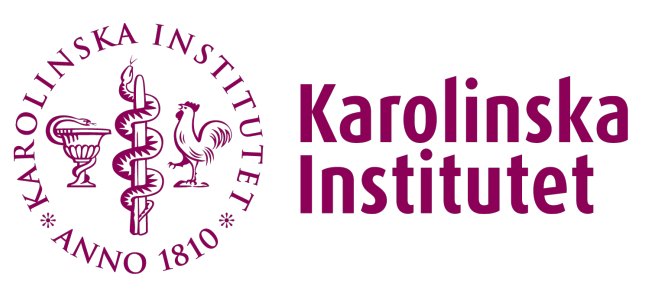

Karolinska Institutet

http://openarchive.ki.se

This is a Peer Reviewed Manuscript version of the following article, accepted for publication in World Psychiatry.

\title{
Psychotic experiences as a predictor of the natural course of suicidal ideation : a Swedish cohort study
}

Kelleher, Ian; Cederlöf, Martin; Lichtenstein, Paul

World Psychiatry. 2014 Jun;13(2):184-8.

http://doi.org/10.1002/wps.20131

http://hdl.handle.net/10616/44754

If not otherwise stated by the Publisher's Terms and conditions, the manuscript is deposited under the terms of the Creative Commons Attribution-NonCommercial-NoDerivatives License (http://creativecommons.org/licenses/by-nc-nd/4.0/), which permits non-commercial re-use, distribution, and reproduction in any medium, provided the original work is properly cited, and is not altered, transformed, or built upon in any way. 


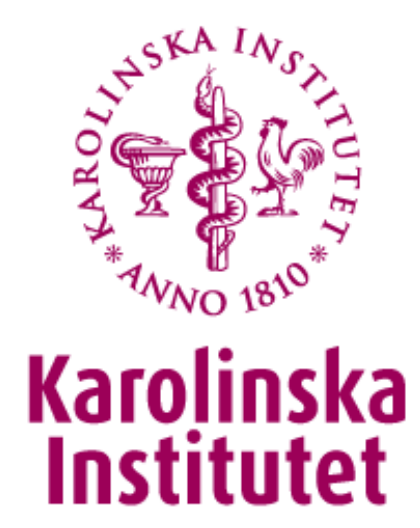

This is an author produced version of a paper published by World Psychiatry. This paper has been peer-reviewed but does not include the final publisher proof-corrections or journal pagination.

\section{Kelleher, Ian; Cederlöf, Martin; Lichtenstein, Paul \\ Psychotic experiences as a predictor of the natural course of suicidal ideation: a Swedish cohort study.}

World Psychiatry. 2014 Jun;13(2):184-8.

DOI: $10.1002 /$ wps.20131

Access to the published version may require subscription. Published with permission from: Wiley 


\section{Psychotic experiences as a predictor of the natural course of suicidal ideation: a Swedish cohort study}

Word count: 2,238

Number of Tables: 2

Running head: Psychotic experiences and the natural course of suicidal ideation

Byline: Ian Kelleher MD, PhD, Martin Cederlöf MSc, Paul Lichtenstein PhD

Corresponding author: Ian Kelleher email: iankelleher@rcsi.ie

Affiliations:

Dr Kelleher, Karolinska Institute, National Centre for Suicide Research and Prevention of Mental IIIHealth (NASP), Granits vag 4, 17177 Stockholm, Sweden.

Mr Cederlöf and Dr Lichtenstein, Karolinska Institute, Department of Medical Epidemiology and Biostatistics, Nobels vag 12A, 17177 Stockholm, Sweden.

The authors report no conflicts of interest.

Financial disclosure: None

Acknowledgements:

This work was funded by the Swedish Research Council and Swedish Research Council for Health, Working Life and Welfare. We sincerely thank the adolescents and their parents who participated in this study. 


\begin{abstract}
Psychotic experiences are far more prevalent in the population than psychotic disorders and are associated with a wide range of depressive, anxiety and behavioral disorders, as well as increased risk for psychotic disorder. Recently, psychotic experiences have been highlighted as a potentially valuable clinical marker of risk for suicidal behavior. There have been few studies to date, however, to assess psychotic experiences as a predictor of suicidality over time. We wished to assess whether young persons with suicidal ideation at baseline assessment who reported psychotic experiences were at higher risk for persistence of suicidal ideation at follow up than young persons who also reported suicidal ideation at baseline but who did not report co-occurring psychotic experiences. A total of 2,263 adolescents were assessed at ages 13 to 14 years for psychotic experiences, suicidal ideation and internalizing and externalizing psychopathology. Participants were re-assessed at ages 16 to 17 years and 19 to 20 years. Among 13- to 14-year olds with suicidal ideation, co-occurring psychotic experiences did not predict an increased odds of persistence of suicidal ideation to 16 to 17 years $(\mathrm{OR}=0.94,95 \% \mathrm{Cl}=0.19-4.78)$. Among 16 - to 17 -year olds with suicidal ideation, however, cooccurring psychotic experiences predicted a 6 -fold increased odds of persistence of suicidal ideation to ages 19 to 20 years $(\mathrm{OR}=5.53,95 \% \mathrm{Cl}=1.33-23.00)$ Psychotic experiences are an important but under-recognized marker of risk for persistence of suicidal ideation, in particular from midadolescence. An increased emphasis on the clinical assessment of psychotic experiences in mental health services should be a priority.
\end{abstract}




\section{Introduction}

Suicidal thoughts and behavior represent major sources of morbidity and mortality worldwide $(1,2)$. There are an estimated one million lives lost by suicide each year (3) and a much larger number of individuals who report suicidal ideation. Although most suicidal ideation is transient and does not require close clinical attention (4), for some individuals, suicidal ideation becomes persistent, causing long-term morbidity, mental distress and ultimately increasing the risk of attempted and completed suicide (5). Identification of individuals whose suicidal ideation is likely to become persistent, however, is a complex challenge in clinical psychiatry. Clinical severity of psychopathology, most notably depression, is a known risk marker for persistence of suicidal ideation $(4,6)$ but, given that symptomatic severity is a continuous measure, it has limited clinical utility in terms of identifying specific individuals as being at 'high risk'.

Recently, psychotic experiences have emerged in the literature as potentially important markers of risk for suicidality (7-10). As opposed to true psychotic symptoms, psychotic experiences are mainly attenuated in nature; that is, hallucinatory and delusional experiences with intact reality testing. For example, a person may report hearing a voice speaking in the absence of an external stimulus but, unlike in frank psychosis, the individual will usually accept that the voice is, in fact, a product of their own mind. Psychotic experiences are far more common in the population than frank psychosis, especially in young people. A meta-analysis of all community studies found that $17 \%$ of children and $7.5 \%$ of adolescents in the general population report psychotic experiences (11). A meta-analysis of longitudinal studies demonstrated that $7.4 \%$ of individuals who report psychotic experiences go on to develop a psychotic illness (12). However, psychotic experiences are associated with a wide variety of mental disorders, not limited to psychosis (13-18). In fact, recent research has found that the majority of community-based individuals with psychotic experiences have at least 1 non-psychotic Axis-1 disorder (17), including depressive, anxiety and behavioral disorders. 
Recent cross sectional research has demonstrated a strong association between psychotic experiences and suicidality $(7,10,19)$ and two longitudinal reports have demonstrated high risk of suicide attempts in population samples who report psychotic experiences $(9,20)$. We wished to investigate whether psychotic experiences would act as a risk marker for the persistence of suicidal ideation in a longitudinal study of Swedish adolescents followed to early adulthood, something that has not been addressed in the literature to date. Specifically, we assessed whether young people with suicidal ideation who reported co-occurring psychotic experiences were more likely to also report suicidal ideation at follow up compared to young people who reported suicidal ideation but did not report psychotic experiences, since this could provide a valuable clinical risk marker to identify individuals at high risk of persistence of suicidal ideation. 


\section{Method}

\section{Sample}

This study was based on data from the Swedish Twin Study of Child and Adolescent Development (TCHAD) (21). The target sample consisted of all 2960 twins born in Sweden between May 1985 and December 1986 who were alive and residing in Sweden in 1994. They were assessed 3 times via mailed questionnaires: at ages 13 to 14,16 to 17 , and 19 to 20 years. Response rates at different waves were as follows: at ages 13 to 14 , parents $=1063(73 \%)$, children $=2263(78 \%)$; at ages 16 to 17 , parents $=1067(74 \%)$, children $=2369(82 \%)$; at ages 19 to 20, parents $=1158(78 \%)$, children $=$ $1705(58 \%)$. Attrition did not vary by psychotic symptoms at 16 to 17 year follow up $\left(x^{2}<0.01, p=0.98\right)$ or 19 to 20 year follow up $\left(x^{2}=0.65, p=0.42\right)$.

\section{Measures}

\section{Suicidal ideation and psychopathology}

Suicidal ideation was assessed at each time point based on the endorsement of the following item from the Youth Self Report (YSR) when the participants were aged 13 to 14 and 16 to 17 years and using the Adult Self-Report (ASR) when the participants were aged 19 to 20 years: "I think about killing myself". There was no information on suicide attempts. Symptoms of psychopathology were also assessed using the YSR/ASR. Internalizing psychopathology (such as depressed mood, anxiety, withdrawn behavior) was self-rated using the internalizing scale of the YSR when the participants were aged 13 to 14 and 16 to 17 and using the ASR when the participants were aged 19 to 20 . Externalizing psychopathology (such as attention problems, hyperactivity, antisocial behavior) was parent-rated using the externalizing scale of the Child Behavior Checklist (CBCL) when the participants were aged 13 to 14 and 16 to 17 and using the Adult Behavior Checklist $(A B C L)$ when the participants were aged 19 to 20. The YSR, ASR, CBCL, and ASR are standardized questionnaires for parents and children to rate the children's frequency and intensity of emotional and behavioral problems exhibited in the past 6 months. The psychometric properties of these scales have been examined in both population-based and clinical samples, presenting good reliability, as well as 
convergent and discriminative validity $(22,23)$. All items were scored on a 3-point scale $(0=$ not true; 1 = sometimes true; and 2 = often true). The YSR is based on self-ratings but consists of the same items as those in the CBCL. The ABCL and ASR consist of similar or developmentally appropriate counterparts of items used in CBCL and YSR. Total scores were calculated at each time point for internalizing and externalizing problems and these were controlled for in our analyses of the relationship between suicidal ideation and psychotic experiences.

\section{Psychotic Experiences}

Psychotic experiences were assessed at each time point using the following item from the YSR/ASR, "I hear sounds or voices that other people think aren't there". This item has previously been shown to have good positive and negative predictive value for clinically verifiable psychotic experiences (24). In a community survey of adolescents, this item not only detected young people with auditory hallucinations (compared to clinical-interview verified auditory hallucinations, positive predictive value $=71 \%$, negative predictive value $=90 \%$ ), but psychotic experiences in general (frank and attenuated hallucinations and delusions) (positive predictive value 100\%, negative predictive value 88\%) (24). Therefore, this item was specifically selected to assess for psychotic experiences in our sample at all 3 time points.

\section{Statistical analyses}

Selective attrition of participants with psychotic experiences was tested using chi squares. We report the prevalence of psychotic experiences and suicidal ideation at each assessment point. We used logistic regression to assess the relationship between internalizing/externalizing psychopathology and psychotic experiences at follow up and between cannabis use and psychotic experiences at follow up. We then used logistic regression to assess whether individuals with suicidal ideation at ages 13 to 14 years who reported psychotic experiences were more likely to have persistent suicidal ideation at ages 16 to 17 years follow up. We then repeated this analysis for individuals with suicidal ideation at ages 16 to 17 years who reported psychotic experiences compared to those who did not report cooccurring psychotic experiences. Analyses on the relationship between psychotic experiences and suicidal ideation were controlled for sex, internalizing and externalizing psychopathology scores, and 
cannabis use. A robust sandwich estimator was used to account for potential clustering as a result of the use of twin data. 


\section{Results}

\section{Prevalence and persistence of suicidal ideation and psychotic experiences}

Suicidal ideation was reported by 11613 - to 14 -year olds (5\%), 19116 - to 17 -year olds (8\%) and 138 19- to 20 -year olds (8\%). Thirty five percent of 13 - to 14 -year olds who reported suicidal ideation had persistent suicidal ideation at 16 to 17 years and $29 \%$ of 16 - to 17 -year olds who reported suicidal ideation had persistent suicidal ideation at 19 to 20 years (see Table 1).

Psychotic experiences were reported by 16213 - to 14 -year olds (7.3\%), 8916 - to 17 -year olds (3.9\%) and 4419 - to 20 -year olds (2.6\%). Sixteen percent of 13 - to 14 -year olds who reported psychotic experiences had persistent psychotic experiences at 16 to 17 years. Nineteen percent of cases of 16 to 17-year olds who reported psychotic experiences had persistent psychotic experiences at 19 to 20 years.

Internalizing and externalizing psychopathology, cannabis use and psychotic experiences Internalizing and externalizing psychopathology scores at ages 13 to 14 years predicted psychotic experiences at ages 16 to 17 years (respectively, $\mathrm{OR}=1.08, \mathrm{Cl} 95=1.05-1.11 ; \mathrm{OR}=1.06, \mathrm{Cl} 95=1.03-$ 1.10). Internalizing and externalizing psychopathology scores at ages 16 to 17 years predicted psychotic experiences at ages 19 to 20 years (respectively, $\mathrm{OR}=1.09, \mathrm{Cl} 95=1.06-1.13 ; \mathrm{OR}=1.04$, $\mathrm{Cl} 95=1.00-1.08)$. There was a non-significant trend for cannabis use at ages 13 to 14 years to predict psychotic experiences at 16 to 17 years (OR=1.28, $\mathrm{Cl} 95=0.69-2.40)$. Cannabis use at ages 16 to 17 years predicted psychotic experiences at ages 19 to 20 years (OR=3.79, $\mathrm{Cl} 95=1.45-9.87)$. We controlled for internalizing and externalizing psychopathology, for cannabis use and for sex in the subsequent analyses on the relationship between psychotic experiences and suicidality (below). 


\section{Psychotic experiences as a marker of risk for future suicidal ideation}

Among adolescents with suicidal ideation at ages 13 to 14 years, co-occurring psychotic experiences did not predict an increased odds of persistence of suicidal ideation to ages 16 to 17 years (see Table 2). Among adolescents with suicidal ideation at ages 16 to 17 years, however, co-occurring psychotic experiences predicted a 6 -fold increased odds of persistence of suicidal ideation to ages 19 to 20 years. In fact, while $27 \%$ of 16 to 17 year olds with suicidal ideation but who did not report psychotic experiences had persistent suicidal ideation at ages 19 to 20 , more than half $(54 \%)$ of 16 to 17 year olds with suicidal ideation and who also reported co-occurring psychotic experiences had persistent suicidal ideation at ages 19 to 20 years (see Table 2). 


\section{Discussion}

In a longitudinal study of a community adolescent sample, we found that psychotic experiences were a strong marker of risk for persistence of suicidal ideation from mid adolescence to late adolescence/early adulthood. This was the case even after controlling for internalizing and externalizing psychopathology. Psychotic experiences in early adolescence (ages 13 to 14) did not predict an increased risk for persistence of suicidal ideation to mid adolescence. This is consistent with research demonstrating that psychotic experiences are more closely associated with severe psychopathology from mid adolescence onward compared to childhood and early adolescence (17). In early adolescence, then, psychotic experiences may be less informative about risk for suicidal behavior than is the case from mid adolescence. It is also possible that younger adolescents are more likely to misinterpret questions on psychotic experiences, although previous research has shown that the item used in the current research is generally well understood even from early adolescence (24).

While it is well recognized that frank psychotic symptoms are associated with higher risk for suicidal behavior, for example in the case of major depressive disorder with psychotic features, the results of the current study demonstrate that a much broader and more prevalent class of (attenuated) psychotic experiences also mark high risk for suicidality. Suicidal ideation among 16- to 17-year olds persisted to 19 to 20 year for just a minority $(27 \%)$ of those who did not report psychotic experiences. However, suicidal ideation persisted to $19-20$ years for the majority (54\%) of 16 - to 17 -year olds who reported co-occurring psychotic experiences.

There are a number of reasons why psychotic experiences may act as a marker of increased risk for suicidal behavior. Several risk factors for psychotic experiences have also been independently demonstrated in cohorts with suicidal behavior (25-29). Notably, psychotic experiences are associated with multimorbid Axis-1 psychopathology, that is the presence of multiple comorbid diagnoses $(17,19)$, an established risk factor for suicidal behavior (25). Young people with psychotic experiences have been shown to have poorer global/socio-occupational functioning, even compared 
to other young people with psychopathology but who do not report psychotic experiences (19), and to have neurocognitive deficits in processing speed in particular $(30,31)$, the most replicated cognitive deficit in individuals with suicidal behavior (26). Psychotic experiences have also been shown to have a strong relationship with childhood trauma, such as physical and sexual abuse, bullying and exposure to domestic violence (32-41). Other research has shown that individuals who report psychotic experiences have increased sensitivity to stress (42) and poorer coping skills $(43,44)$ factors that might also contribute to risk for suicidality in the context of life stressors. Emerging neuroimaging research is also demonstrating interesting overlap between these groups, including showing volumetric differences in the cingulum and orbitofrontal cortex in young people with psychotic experiences (45), two centers known to be important in stress regulation (46) and which have been highlighted in imaging studies of individuals with suicidal behavior (47).

\section{Strengths and limitations}

A strength of the current study is the longitudinal nature. We were also able to assess, for the first time, the relationship between suicidal ideation and psychotic experiences through early to late adolescence and into early adulthood. A limitation is that, while the data allowed us to look at risk for later suicidal ideation, we were not able to identify who in this group had clear suicide intent or suicide attempts; however, persistent suicidal ideation, and the long term psychological distress associated with it, are important outcomes in their own right in addition to the importance of deaths from suicide. Although our sample was relatively large, subgroup analyses involved relatively small groups and, because of this, confidence intervals were wide. Response rates were good for both young people and parents at ages 13 to 14 and 16 to 17 but were lower than desirable among young people at ages 19 to 20 (58\% of young people versus $78 \%$ of parents); however, participation did not vary by psychotic experiences.

\section{Conclusion}

In a longitudinal study, we found that psychotic experiences were a strong clinical risk marker for the persistence of suicidal ideation from mid-adolescence into late adolescence and early adulthood. This 
finding was not explained by internalizing or externalizing psychopathology or by cannabis use. These results highlight the need for an increased emphasis on the clinical assessment of (attenuated and frank) psychotic experiences in mental health services: the presence of psychotic experiences should alert the clinician that suicidal ideation is unlikely to be transient - in the current research, suicidal ideation was still present 3 years later for the majority of 16- to 17-year olds with suicidal ideation who reported co-occurring psychotic experiences. Given the public health importance of suicidal behavior worldwide, further research to develop our understanding of this relationship, and the mechanisms that underlie it, should be a priority. 
1. Organization WH. The World Health Report 2001: Mental Health, New Understanding, New Hope. Geneva World Health Organization; 2001.

2. Wasserman $D$, Cheng $Q$, Jiang GX. Global suicide rates among young people aged 15-19. World Psychiatry. 2005;4: 114-120.

3. The global burden of disease: 2004 update. 2008. http://www.who.int/evidence/bod. Published Last Modified Date|. Accessed Dated Accessed|.

4. Garrison $\mathrm{CZ}$, Addy $\mathrm{CL}$, Jackson KL, McKeown RE, Waller JL. A longitudinal study of suicidal ideation in young adolescents. J Am Acad Child Adolesc Psychiatry. 1991;30: 597-603.

5. Borges G, Angst J, Nock MK, Ruscio AM, Kessler RC. Risk factors for the incidence and persistence of suicide-related outcomes: a 10-year follow-up study using the National Comorbidity Surveys. J Affect Disord. 2008;105: 25-33.

6. Wilcox HC, Arria AM, Caldeira KM, Vincent KB, Pinchevsky GM, O'Grady KE. Prevalence and predictors of persistent suicide ideation, plans, and attempts during college. J Affect Disord. 2010;127: 287-294.

7. Kelleher I, Lynch F, Harley $M$, et al. Psychotic symptoms in adolescence index risk for suicidal behavior: findings from two population-based case-control clinical interview studies. Arch Gen Psychiatry. 2012;69: 1277-1283.

8. Nishida A, Sasaki T, Nishimura Y, et al. Psychotic-like experiences are associated with suicidal feelings and deliberate self-harm behaviors in adolescents aged 12-15 years. Acta Psychiatr Scand. 2010;121: 301-307.

9. Kelleher I, Corcoran P, Keeley $\mathrm{H}$, et al. Psychotic symptoms and population risk for suicide attempt: a prospective cohort study. JAMA Psychiatry. 2013.

10. Saha S, Scott JG, Johnston AK, et al. The association between delusional-like experiences and suicidal thoughts and behaviour. Schizophr Res. 2011.

11. Kelleher I, Connor D, Clarke MC, Devlin N, Harley M, Cannon M. Prevalence of psychotic symptoms in childhood and adolescence: a systematic review and meta-analysis of population-based studies. Psychol Med. 2012;42: 1857-1864.

12. Linscott RJ, van Os J. An updated and conservative systematic review and meta-analysis of epidemiological evidence on psychotic experiences in children and adults: on the pathway from proneness to persistence to dimensional expression across mental disorders. Psychol Med. 2013;43: 1133-1149.

13. Yung AR, Buckby JA, Cosgrave EM, et al. Association between psychotic experiences and depression in a clinical sample over 6 months. Schizophr Res. 2007;91: 246-253.

14. Scott J, Martin G, Bor W, Sawyer M, Clark J, McGrath J. The prevalence and correlates of hallucinations in Australian adolescents: results from a national survey. Schizophr Res. 2009;107: 179-185.

15. Wigman JT, van Nierop M, Vollebergh WA, et al. Evidence that psychotic symptoms are prevalent in disorders of anxiety and depression, impacting on illness onset, risk, and severity--implications for diagnosis and ultra-high risk research. Schizophr Bull. 2012;38: 247-257.

16. Bartels-Velthuis AA, van de Willige G, Jenner JA, van Os J, Wiersma D. Course of auditory vocal hallucinations in childhood: 5-year follow-up study. Br J Psychiatry. 2011.

17. Kelleher I, Keeley $\mathrm{H}$, Corcoran $\mathrm{P}$, et al. Clinicopathological significance of psychotic experiences in non-psychotic young people: evidence from four population-based studies. $\mathrm{Br}$ J Psychiatry. 2012;201: 26-32.

18. Addington J, Cornblatt BA, Cadenhead KS, et al. At clinical high risk for psychosis: outcome for nonconverters. Am J Psychiatry. 2011;168: 800-805. 
19. Kelleher I, Devlin N, Wigman JTW, et al. Psychotic experiences in an adolescent mental health clinic sample: implications for suicidality, multimorbidity and functioning. Psychol Med. In Press.

20. Fisher HL, Caspi A, Poulton R, et al. Specificity of childhood psychotic symptoms for predicting schizophrenia by 38 years of age: a birth cohort study. Psychol Med. 2013: 1-10.

21. Tuvblad C, Narusyte J, Grann M, Sarnecki J, Lichtenstein P. The genetic and environmental etiology of antisocial behavior from childhood to emerging adulthood. Behav Genet. 2011;41: 629-640.

22. Achenbach T. Manual for the Youth Self - Report and 1991 Profile. Burlington, VT: University of Vermont, Department of Psychiatry. 1991.

23. Achenbach T, Rescorla L. Manual for the ASEBA Adult Forms and Profiles. Burlington: University of Vermont, Research Center for Children, Youth and Families; 2003.

24. Kelleher I, Harley M, Murtagh A, Cannon M. Are screening instruments valid for psychoticlike experiences? A validation study of screening questions for psychotic-like experiences using in-depth clinical interview. Schizophr Bull. 2011;37: 362-369.

25. Lewinsohn PM, Rohde P, Seeley JR. Adolescent psychopathology: III. The clinical consequences of comorbidity. J Am Acad Child Adolesc Psychiatry. 1995;34: 510-519.

26. LeGris J, van Reekum R. The neuropsychological correlates of borderline personality disorder and suicidal behaviour. Can J Psychiatry. 2006;51: 131-142.

27. Dube SR, Anda RF, Felitti VJ, Chapman DP, Williamson DF, Giles WH. Childhood abuse, household dysfunction, and the risk of attempted suicide throughout the life span: findings from the Adverse Childhood Experiences Study. JAMA. 2001;286: 3089-3096.

28. Angst J, Sellaro R, Ries Merikangas K. Multimorbidity of psychiatric disorders as an indicator of clinical severity. Eur Arch Psychiatry Clin Neurosci. 2002;252: 147-154.

29. Lopez-Castroman J, Melhem N, Birmaher B, et al. Early childhood sexual abuse increases suicidal intent. World Psychiatry. 2013;12: 149-154.

30. Kelleher I, Clarke MC, Rawdon C, Murphy J, Cannon M. Neurocognition in the extended psychosis phenotype: performance of a community sample of adolescents with psychotic symptoms on the MATRICS neurocognitive battery. Schizophr Bull. 2012.

31. Barnett JH, McDougall F, Xu MK, Croudace TJ, Richards M, Jones PB. Childhood cognitive function and adult psychopathology: associations with psychotic and non-psychotic symptoms in the general population. Br J Psychiatry. 2012;201: 124-130.

32. Kelleher $\mathrm{I}$, Keeley $\mathrm{H}$, Corcoran $\mathrm{P}$, et al. Childhood trauma and psychosis in a prospective cohort study: Cause, effect and directionality. Am J Psychiatry. 2013.

33. Arseneault L, Cannon M, Fisher HL, Polanczyk G, Moffitt TE, Caspi A. Childhood trauma and children's emerging psychotic symptoms: A genetically sensitive longitudinal cohort study. Am J Psychiatry. 2011;168: 65-72.

34. Read J, van Os J, Morrison AP, Ross CA. Childhood trauma, psychosis and schizophrenia: a literature review with theoretical and clinical implications. Acta Psychiatr Scand. 2005;112: 330-350.

35. Scott J, Chant D, Andrews G, Martin G, McGrath J. Association between trauma exposure and delusional experiences in a large community-based sample. Br J Psychiatry. 2007;190: 339-343.

36. Saha $\mathrm{S}$, Varghese $\mathrm{D}$, Slade $\mathrm{T}$, et al. The association between trauma and delusional-like experiences. Psychiatry Res. 2011;189: 259-264.

37. Fisher HL, Schreier A, Zammit S, et al. Pathways between childhood victimization and psychosis-like symptoms in the ALSPAC birth cohort. Schizophr Bull. 2012.

38. Bentall RP, Wickham S, Shevlin M, Varese F. Do specific early-life adversities lead to specific symptoms of psychosis? A study from the 2007 the adult psychiatric morbidity survey. Schizophr Bull. 2012;38: 734-740. 
39. Freeman D, Fowler D. Routes to psychotic symptoms: trauma, anxiety and psychosis-like experiences. Psychiatry Res. 2009;169: 107-112.

40. Heins $M$, Simons $C$, Lataster $T$, et al. Childhood trauma and psychosis: a case-control and case-sibling comparison across different levels of genetic liability, psychopathology, and type of trauma. Am J Psychiatry. 2011;168: 1286-1294.

41. Janssen I, Krabbendam L, Bak M, et al. Childhood abuse as a risk factor for psychotic experiences. Acta Psychiatr Scand. 2004;109: 38-45.

42. Lataster $\mathrm{T}$, Wichers $\mathrm{M}$, Jacobs $\mathrm{N}$, et al. Does reactivity to stress cosegregate with subclinical psychosis? A general population twin study. Acta Psychiatr Scand. 2009;119: 45-53.

43. Lin A, Wigman JT, Nelson B, et al. The relationship between coping and subclinical psychotic experiences in adolescents from the general population - a longitudinal study. Psychol Med. 2011: 1-12.

44. Wigman JTW, Devlin N, Kelleher I, et al. Coping as a moderating factor between psychotic symptoms and functioning in adolescents with mental illness. Submitted.

45. Jacobson $\mathrm{S}$, Kelleher I, Harley $\mathrm{M}$, et al. Structural and functional brain correlates of subclinical psychotic symptoms in 11-13 year old schoolchildren. Neuroimage. 2010;49: 1875-1885.

46. Koolschijn PC, van Haren NE, Lensvelt-Mulders GJ, Hulshoff Pol HE, Kahn RS. Brain volume abnormalities in major depressive disorder: a meta-analysis of magnetic resonance imaging studies. Hum Brain Mapp. 2009;30: 3719-3735.

47. Monkul ES, Hatch JP, Nicoletti MA, et al. Fronto-limbic brain structures in suicidal and nonsuicidal female patients with major depressive disorder. Mol Psychiatry. 2007;12: 360-366. 
Table 1: Baseline suicidal ideation and risk for suicidal ideation at follow up assessment

\begin{tabular}{|c|c|c|c|c|c|}
\hline & \multirow[t]{2}{*}{$\mathrm{N}$} & \multicolumn{2}{|c|}{ Suicidal ideation at follow up } & \multirow[t]{2}{*}{ OR } & \multirow[t]{2}{*}{$95 \% \mathrm{Cl}$} \\
\hline & & $\%$ & $\mathrm{n}$ & & \\
\hline Suicidal ideation at 13 to 14 years & 116 & $34.9 \%$ & 37 & 4.17 & $2.80-6.20$ \\
\hline Suicidal ideation at 16 to 17 years & 191 & $29.4 \%$ & 42 & 3.90 & $2.78-5.46$ \\
\hline
\end{tabular}

Follow up for 13 to 14 year olds was at ages 16 to 17 years; follow up for 16 to 17 year olds was at ages 19 to 20 years. 
Table 2: Risk for suicidal ideation at follow up assessment in adolescents with baseline suicidal ideation plus or minus psychotic experiences

\begin{tabular}{|c|c|c|c|c|c|c|c|}
\hline & \multirow[t]{2}{*}{$\mathrm{N}$} & \multicolumn{2}{|c|}{ No psychotic experiences } & \multicolumn{2}{|c|}{ Psychotic experiences } & \multirow[t]{2}{*}{ OR } & \multirow[t]{2}{*}{$95 \% \mathrm{Cl}$} \\
\hline & & $\mathrm{n}$ & $\begin{array}{c}\% \text { with suicidal ideation } \\
\text { at follow up }\end{array}$ & $\mathrm{n}$ & $\begin{array}{l}\text { \% with suicidal } \\
\text { ideation at follow up }\end{array}$ & & \\
\hline Suicidal ideation at 13 to 14 years & 109 & 88 & $31 \%$ & 21 & $29 \%$ & 0.94 & $0.19-4.78$ \\
\hline Suicidal ideation at 16 to 17 years & 179 & 156 & $27 \%$ & 23 & $54 \%$ & 5.53 & $1.33-23.00$ \\
\hline
\end{tabular}

Follow up for 13 to 14 year olds was at ages 16 to 17 years; follow up for 16 to 17 year olds was at ages 19 to 20 years. Analyses were controlled for sex, internalizing psychopathology score, externalizing psychopathology score and cannabis use. 